\title{
How technology can reduce our impact on the Earth
}

\section{Prudent use of innovations could avoid sacrificing the present for the future, or vice versa.}

Sir - William E. Rees, in his Concepts

essay "A blot on the land" (Nature 421, 898;

2003), uses the ecological-footprint

concept to argue that the 'carrying capacity' of the Earth has been exceeded because of technological and economic growth, and to counter some some economists' claims that the carrying capacity can increase indefinitely. The critical point, unrecognized by either side, is not whether the carrying capacity can increase indefinitely but whether it can increase rapidly enough to accommodate the environmental and economic expectations of a world that grows wealthier as its population growth rate slows dramatically.

Paradoxically, both technology and economic development provide the means to solve the very problems they create. Without technological development in the first instance, the human population would be smaller, because higher birth rates would have been offset by higher mortality rates. Dispensing with present technology now would undoubtedly be catastrophic in human terms - people would be hungrier, unhealthier and shorter-lived, without the world necessarily becoming ecologically more stable.

Similarly, foregoing economic development, which helps to generate wealth, would also be calamitous (see I. M. Goklany, Case Western Law Review; in the press). Only wealthy countries can afford the scientific infrastructure to research, develop and put into use clean technologies that increase the Earth's carrying capacity.

For all of these reasons, the richest countries, not surprisingly, are also the most technologically advanced. They have the highest crop yields per hectare, which is inversely related to the demand for land, a primary element in the ecological footprint. Inefficient agriculture creates pressures for new agricultural land at the expense of virgin forest or marginal lands in countries with growing populations. If agricultural-technology development had been frozen in 1961, we estimate, using data from the Food and Agriculture Organisation (see FAOSTAT 2003: apps.fao.org), that cropland would have had to increase from its present $11 \%$ to some $25 \%$ of the planetary surface to produce the same amount of food now.

Accepting Rees's estimate that we currently exceed the Earth's carrying capacity by one-fifth, without technological development we would now exceed it by one-third. Virtually no natural forest would now remain and the rest of nature would be even more embattled. Yes, we recognize that current agricultural technology, with its reliance on pesticides and fertilizers, created many new problems even as it solved old ones, but that is exactly why we favour technological change. New technologies need not be perfect, but they should improve on current versions. That is why we support prudent use of agricultural biotechnology - another imperfect technology, but vastly superior to conventional technologies. The trick is not to sacrifice the present for the future, or vice versa. Without technological change and economic development, there can be no solution to the predicament of meeting human needs while containing human impact on the planet. Although neither technological change nor economic development is a panacea, they make a solution more likely.

Indur M. Goklany ${ }^{\star}$, Anthony J. Trewavas $\dagger$

${ }^{*}$ US Department of the Interior, 1849 C Street NW, Washington, DC 20240, USA (The views expressed here are not necessarily those of any branch of the US Government)

$\dagger$ Institute of Cell and Molecular Biology, King's Buildings, University of Edinburgh, Edinburgh EH9 3JH, Scotland

\section{Unbalanced view of a dynamic world}

Sir - Sandra Knapp, in her Concepts essay about conservation, "Dynamic diversity" (Nature 422, 475), correctly and succinctly presents an analysis of a major conceptual problem facing conservationists: that preserving nature is not about stasis, but about maintaining the ever-evolving variety of life of Earth. Since the middle of the nineteenth century there has been abundant evidence that the Earth has been, and will continue to be, a complex, everchanging series of habitats and associated species, of which we experience only a snapshot in our lifetimes. Our conundrum is that while we know this, we seem unable to take the required long perspective implied by Knapp's plea for a dynamic view of the natural world.

Why do we cling to this static view of nature, which is deeply embedded in popular understanding of the natural world as well as in the thinking of politicians and policy-makers interested in conservation and sustainability? This misunderstanding of the natural world can be summed up in a phrase that we constantly hear from the media, environmental groups, politicians and in casual conversation: "the balance of nature". The idea that nature is, or should be, "in balance" is deeply ingrained. But there is not, and never has been, a balance of nature.

Balance is a seductive concept as it suggests that opposites can be equated and, in the final analysis, traded. But it is not possible to equate humans and elephants, woodlands and meadows, tonnes of carbon emissions with hectares of new forest, and so on, unless it is by reference to an arbitrary, external concept. In the marketplace, this arbitrary concept is money. Economists are now attempting to balance natural processes, habitats and species using the abstraction of their monetary value, on the assumption that cash can be the final arbiter of the difficult value judgements necessary for custody of the planet and its natural processes.

It is now surely time to abandon this way of thinking. We now need to embrace — in science, popular culture and politics - the phrase "the dynamic diversity of nature". It may not be as catchy as "the balance of nature”, but wide exposure should eventually see it embedded in our lexicon of aphorisms.

Graham Martin

School of Biosciences, University of Birmingham, Edgbaston, Birmingham B15 2TT, UK

\section{Lack of trained security staff delays US visas}

Sir - Your News story "Researchers rage at tightened restrictions on US immigration" (Nature 422, 457-458; 2003) highlights a growing impediment to international science and technology collaborations. For scientists, students and would-be terrorists wanting to enter the United States, the initial point of contact with immigration policies and practices is the US consularaffairs officer in their own country. This is usually a junior Foreign Service officer typically new to the country and the local language, lacking in scientific or technical training, and demoralized by long lines of anxious applicants and by highly regulated routine work assignments. Consular Affairs is one of five job categories or 'cones' within the State Department. It is the least attractive cone among career Foreign Service officers. Its workload is expected to rise to 12 million nonimmigration visa applications by 2005 
(according to a report in the Foreign Service Journal, March 2001), making visa and passport services an even less attractive profession.

Last August, consular officers received updated State Department instructions on how to apply the Technology Alert List and the list of 'state sponsors of terrorism' to the visa-screening process. Ideally, consular staff should be augmented by intelligence and law-enforcement personnel trained to recognize suspect applicants, and others with scientific or technical backgrounds. Instead, the current officers have been instructed to post these two 'cheat sheet' lists at the "interview windows where the staff can become familiar with the contents". (The department's updated instruction cable is available online at http://travel.state.gov/state147566.html.)

The visa staffing, instructions and evolving interagency review process seem guaranteed to further slow the entry of foreign scientists, students and visitors into the United States. For now, official Washington appears to be content with that frustrating backlog, as suggested by congressional comments such as: "Our security is more important than your convenience." That attitude is likely to endure until the airlines, tourism and other global industries begin to make the same complaints that the scientific community is making now.

\section{Edward McSweegan}

US State Department Diplomacy Fellow (1986-1987), 1692 Barrister Court, Crofton, Maryland 21114, USA

\section{Designer scientific literature}

Sir-Your News report " "Axeing of website article sparks row at Max Planck", describing the removal of several hundred web pages discussing a concept called 'intelligent design' (ID), is welcome.

In Germany, efforts to undermine evolution education - mostly in the form of ID, which rejects the theory of natural selection - have evolved into a successful campaign, including a standard textbook in its fifth edition, several journals and two professional video films in which proponents of ID such as the microbiologist Siegfried Scherer and the geneticist Wolf-Ekkehard Lönnig give interviews in the laboratories of their government-sponsored departments. The ID strategy is not to identify the 'designer' as God in the Bible or for adherents to call themselves creationists; they have coined the term 'theists' to describe themselves (see ref. 2 for a discussion).

Last year, ID-creationism took a step towards scientific respectability when Lönnig and Heinz Saedler published an review" entitled "Chromosome rearrangements and transposable elements". In this article they summarize arguments against Darwin's concept of gradual evolution with reference to the prominent German anti-Darwinists Otto Heinrich Schindewolf (1896-1971) and Richard Goldschmidt (1878-1958).

Lönnig and Saedler discuss the possibility of "a partly predetermined generation of biodiversity and new species", which they characterize as a "nonselection-driven and autonomous" process. Popular books by ID proponents Michael Behe and William Dembski are cited as credible sources. (For critical reviews of these books, see refs 4 and 5.) Lönnig and Saedler refer to a "wide range of opinions" and cite evolutionists such as Michael J. Benton, Stephen Jay Gould and John Maynard Smith as well as IDcreationists such as Behe and Dembski, and Lönnig's now-removed web pages. On the basis of these references and polemical comments, the authors state that we should welcome all ideas and hypotheses on the origin of life, "wherever they may lead".

In a German video film called Is The Bible Right? There is No Evidence for the Theory of Evolution, Lönnig argues that an intelligent force, endowed with consciousness and spirit, has been at work in the creation of all complex forms of life. This viewpoint is now implicitly proposed as a hypothesis in the scientific literature. ${ }^{3}$

Four years ago, this journal published two excellent editorials 6 , entitled "The difference between science and dogma" and "Combating the exploiters of creationism". I think that the time is ripe to continue this series.

\section{U. Kutschera}

Department of Biology, University of Kassel, Heinrich-Plett-Strasse 40, 34109 Kassel, Germany

1. Abbott, A. Nature 422, 460 (2003).

2. Palevitz, B. A. Evolution 56, 1718-1720 (2002).

3. Lönnig, W. E. \& Saedler, H. Annu. Rev. Gen. 36, 389-410 (2002)

4. Coyne, J. A. Nature 383, 227-228 (1996).

5. Charlesworth, B. Nature 418, 129 (2002).

6. Nature 400, 697 (1999).

7. Nature 402, 843 (1999)

\section{Peer review: recognition via year-end statements}

Sir-Although I agree with T. Clausen and O. B. Nielsen in Correspondence ("Reviewing should be shown in publication list”, Nature 421, 689; 2003) that peer review is a very significant factor in the quality of the scientific literature, their suggestion that peer-review activities should be shown in scientific CVs has practical problems, as they themselves note.
An alternative solution might be for journals to send a letter to their reviewers each year stating how many manuscripts they have reviewed, with some associated measure of quality. This verifiable information should become one criterion for assessment exercises, and would also improve and maintain the general standard of the peer-review system.

The efforts of reviewers should not be underestimated. Even a short and exceptionally well-written manuscript takes at least three or four hours to review properly: more commonly this task takes a day or more. Most manuscripts are revised by their authors and reviewed again by the original reviewers. Two or three reviewers are involved in every manuscript, and about two-thirds of submitted manuscripts are rejected. Hence, on average, each published article has received about 10-15 days of reviewing activity.

Good reviewers may receive one or two manuscripts a month from each journal that knows of them. It follows that these scientists are spending a large percentage of their time on reviewing manuscripts that could otherwise be spent on research, writing and so on (although of course they themselves benefit from peer-review when they submit their own papers).

Editors of journals complain that it is becoming more difficult to attract good reviewers because university researchers increasingly need to earn 'scientific credits'. What is needed, therefore, is a change in attitude from university managers, boards, agencies and others who decide about grants, tenure, promotion and so on.

It has been (and will be) mentioned many times that the current system in which quantity is taken as a measure for academic achievement should be replaced by one that gives credit to quality (Nature 422, 259-261; 2003). Reviewers are chosen because of their quality: their standing in their own discipline and their ability to think critically. An endorsement by a journal could be one way to acknowledge this ability in real terms, by incorporating peer-review activities into the professional career structure. The more prestigious the journal to researchers in the field, the more weight could be given to peerreview activities for that journal by assessment committees.

If reviewers do not receive public credit, the better scientists will eventually no longer be prepared to do this work, which would then devolve to less good reviewers, and the standard of scientific publications would fall.

A. J. (Tom) van Loon

President, European Association of Science Editors, Valle del Portet 17 bajo, 03726 Benitachell, Alicante, Spain 